\title{
INFLUÊNCIA DA FREQUÊNCIA E PARTICIPAÇÃO NO DESEMPENHO EM UM AMBIENTE DE APRENDIZAGEM CENTRADO NO ALUNO
}

\author{
Camila Aparecida Tolentino Cicuto ${ }^{\mathrm{a}, * \odot \odot}$ e Bayardo Baptista Torres ${ }^{\mathrm{b}}$ \\ anniversidade Federal do Pampa, 96450-000 Dom Pedrito - RS, Brasil \\ bDepartamento de Bioquímica, Universidade de São Paulo, 05508-000 São Paulo - SP, Brasil
}

Recebido em 05/08/2019; aceito em 09/10/2019; publicado na web em 16/01/2020

\begin{abstract}
INFLUENCE OF FREQUENCY AND PARTICIPATION ON PERFORMANCE IN A STUDENT-CENTERED LEARNING ENVIRONMENT. The aim of this research was to verify student performance, participation and frequency when they study in a student-centered learning environment. Data collection included the application of questionnaires and semi-structured interviews. Data analysis combined quantitative and qualitative approaches. In the results on frequency and participation, 32\% of the students had a high number of absences and more than $25 \%$ indicated participation less than or equal to 5 (in a 1-10 scale). This is an expressive data, since the low engagement, due to absence in classes, or low participation, in a course aligned with Vygotsky's assumptions, compromises the construction of knowledge. In these environments, it is not enough that the students try to solve the proposed questions by themselves: the adopted strategy presupposes the social interaction as a differential for learning promotion. Regarding performance, $37 \%$ of them were disapproved. To understand the reasons of such unsatisfactory performance, semi-structured interviews were conducted. The analysis of these data revealed that the overload of credits had a great impact on participation and frequency in biochemistry classes. This data indicates the need for integrated curricular organization, without which, even innovative disciplines, with student-centered methods, have discrete possibilities of success.
\end{abstract}

Keywords: active learning; collaborative learning; problem solving; teaching methodology.

\section{INTRODUÇÃO}

A influência da frequência e participação dos alunos no seu desempenho foi investigada em uma disciplina de Bioquímica com carga horária total de 180 horas. Essa disciplina é conduzida por estratégias ativas de ensino-aprendizagem, também conhecidas na literatura como centradas no aluno. Para isso, são utilizados períodos de estudo (PE) e grupos de discussão (GD) em substituição às aulas expositivas clássicas.

Nos PE os acadêmicos são reunidos em grupos de 4-5 componentes e têm como tarefa responder as questões de um roteiro dividido em módulos, cada um dos quais incidindo sobre um tópico da Bioquímica. As questões do roteiro situam-se em nível estabelecido por Zoller como de baixa ordem cognitiva - LOCS, do inglês Low Order Cognitive Skills. ${ }^{1}$ As habilidades de baixa ordem foram exploradas através de questões que exigiam dos alunos conhecer, recordar ou aplicar a informação ou algoritmos. Tipicamente são exercícios e não problemas. Para o estudo, os alunos contam com consulta à literatura, especialmente a um livro texto de Bioquímica, ${ }^{2}$ e com a assessoria do professor e de monitores que orientam o estudo, procurando não oferecer respostas diretas e definitivas, e estimulam os estudantes a colaborarem com os colegas e interagirem. Além disso, os alunos contam com a indicação de softwares para melhor visualização das estruturas e moléculas estudadas na Bioquímica, para simulação de experimentos e para auxiliar a compreensão de processos dinâmicos e complexos, impossíveis de serem ilustrados com figuras estáticas.

Quando todos os estudantes terminam essa etapa, inicia-se o GD. Para essa estratégia, os alunos reúnem-se em grupos com 20-25 participantes para resolver problemas de alta ordem cognitiva - HOCS, do inglês High Order Cognitive Skills, ainda na classificação de Zoller, em discussões coordenadas pelos docentes. As questões de alta ordem exigiram dos alunos habilidades de investigação, resolução de

*e-mail: camilacicuto@unipampa.edu.br problemas, tomada de decisões, além do pensamento crítico. ${ }^{1}$ Essa disciplina é oferecida aos estudantes do primeiro ano da graduação em Farmácia-Bioquímica, sendo ministrada anualmente há cerca de 20 anos pelos mesmos docentes e com essa abordagem centrada no aluno. Assim, as estratégias adotadas (PE e GD) já estão bastante consolidadas no âmbito da disciplina e da literatura. ${ }^{3-6} \mathrm{O}$ estudo e a discussão em grupo fundamentam-se, principalmente, nas contribuições de Vygotsky, ${ }^{7,8}$ relacionadas com a formulação do conceito de zona de desenvolvimento iminente (traduzido por zona de desenvolvimento proximal ou zona de desenvolvimento imediato em traduções pouco cuidadosas). ${ }^{8}$ Esse conceito está ligado à relação existente entre o desenvolvimento, a instrução e a ação colaborativa de outra pessoa, sendo caracterizado pelo nível de desenvolvimento atual e o seu nível de desenvolvimento iminente. O primeiro é caracterizado pelo amadurecimento das funções mentais (operações intelectuais) resultantes de ciclos de desenvolvimento completos, ou seja, refere-se à capacidade de resolver problemas de forma independente. Por sua vez, o nível de desenvolvimento iminente é definido como a capacidade de resolver problemas com a orientação de indivíduos mais qualificados. ${ }^{7,8}$

Os pressupostos vygotskyanos subjazem as estratégias de PE e GD, através do potencial das atividades colaborativas para proporcionar a troca social durante o processo de aprendizagem. Em ambas estratégias desse espaço coletivo, a participação e frequência dos estudantes são imprescindíveis para a construção do conhecimento. Nessa disciplina, o aluno deixa o seu papel passivo de mero ouvinte que reproduz literalmente a fala do professor em avaliações subsequentes e assume o papel de protagonista da própria aprendizagem. $\mathrm{O}$ professor, por sua vez, proporciona atividades que permitem aos estudantes participar ativamente da construção do conhecimento na resolução de problemas. Ele também é responsável por monitorar os alunos durante a realização das atividades e fornecerfeedbacks, assim ele deixa o papel de narrador. Nessa perspectiva, Moreira ${ }^{8}$ argumenta que o papel do professor não é minimizado [...] "tirá-lo do papel de 
narrador não significa, de modo algum, reduzir sua importância. Ao contrário, como mediador e organizador de situações de aprendizagem centradas no aluno, ele ou ela é mais importante do que como narrador(a)" ${ }^{\prime 9}$ (p. 11).

Essa mudança de foco implica em possibilitar que os alunos discutam, negociem significados, interpretem, sistematizem informações, aprendam a tirar as suas próprias conclusões, entre outros aspectos. Nesse sentido, a participação dos estudantes não se restringe apenas à participação oral. A participação deles pressupõe o envolvimento nas diferentes dimensões humanas como a sensório-motor, a afetivo-emocional e a mental-cognitiva. ${ }^{9-14}$ Além disso, é preciso considerar que nem todos têm a mesma desenvoltura para a discussão e que alguns estudantes têm pouca participação oral. No entanto, estão atentos e intelectualmente participando da discussão. A frequência, por sua vez, é o simples fato de o aluno comparecer às aulas. Ao faltar, perde a oportunidade de colaborar com os seus pares e de desenvolver habilidades cognitivas e sociais que são objetivos do ensino centrado no aluno.

A partir das considerações sobre as singularidades desse contexto, tem-se como variáveis de interesse central no presente estudo o/a: desempenho, frequência e participação dos estudantes nas aulas de Bioquímica. Isso se justifica, uma vez que o engajamento deles, em uma disciplina alinhada com os pressupostos do ensino centrado no aluno, interfere no processo de construção do conhecimento. Nesses ambientes não basta que o aluno estude sozinho, pois pressupõem a interação social como diferencial para a promoção da aprendizagem, que sofre impacto negativo pela falta ou baixa participação. Nesse sentido, faz-se necessário investigar essas variáveis em ambientes de aprendizagem que exigem dos acadêmicos uma postura ativa e criativa diante do conhecimento.

Esperava-se com este estudo confirmar ou refutar a existência de relações entre as variáveis em questão e ainda verificar se as colaborações entre os alunos são imprescindíveis para a resolução dos problemas propostos pela disciplina investigada.

\section{OBJETIVO}

O objetivo deste estudo foi analisar as influências da frequência, da participação e interação dos estudantes em um ambiente de aprendizagem centrado no aluno.

\section{METODOLOGIA}

Neste estudo optou-se por uma pesquisa de natureza mista (mixed methods), correspondendo à integração de métodos quantitativos e qualitativos. A justificativa para tal escolha baseia-se no fato de que nem os métodos quantitativos nem os qualitativos são suficientes, por si só, para descrever a complexidade das variáveis ora em análise. Assim, quando usados em combinação, esses possibilitam uma análise mais robusta, aproveitando os pontos fortes de cada uma destas abordagens. ${ }^{15}$

Participaram desta pesquisa 74 alunos, correspondendo a 86,0\% do total de alunos matriculados. Esses estudantes foram convidados a assinar um termo de consentimento livre e esclarecido antes do início da etapa de coleta dos dados. Foram informados sobre as finalidades desta pesquisa e estavam cientes de que os dados obtidos seriam utilizados exclusivamente para fins acadêmicos, bem como divulgados com a preservação do anonimato.

\section{Questionário}

Para a avaliação na vertente quantitativa, foi usado um questionário com quatro itens. Os dois primeiros foram testes de múltipla escolha para os estudantes assinalarem a frequência e motivos para faltar às aulas de Bioquímica. Os outros dois itens apresentavam uma escala numérica de 1-10 ( 1 = pouco e 10 = muito $)$ para que eles indicassem a participação nas atividades colaborativas e também a interferência de outras disciplinas nas aulas de Bioquímica (Quadro 1).

Quadro 1. Questionário de frequência e participação nas atividades colaborativas

- Em geral, quanto você frequentou as aulas da disciplina Bioquímica: Estrutura de Biomoléculas e Metabolismo? a. até $20 \%$ das aulas; b. entre $20 \%$ e $50 \%$ das aulas; c. entre $50 \%$ e $70 \%$ das aulas; d. mais de $70 \%$ das aulas.

- Indique os motivos para você faltar às aulas da disciplina Bioquímica: Estrutura de Biomoléculas e Metabolismo (indique quantas opções julgar necessário): a. Nunca faltei; $b$. Acúmulo de trabalho em outras disciplinas; c. Antes de provas de outras disciplinas; d. Acúmulo de trabalho nesta disciplina; e. Antes de provas desta disciplina; f. Descanso ou lazer.

- Utilize a seguinte escala numérica para indicar a sua participação nas atividades (PE e GD) da disciplina Bioquímica: Estrutura de Biomoléculas e Metabolismo.

$1=$ pouco e $10=$ muito

\begin{tabular}{|l|l|l|l|l|l|l|l|l|l|}
\hline 1 & 2 & 3 & 4 & 5 & 6 & 7 & 8 & 9 & 10 \\
\hline
\end{tabular}

- Utilize a seguinte escala numérica para indicar quanto outras disciplinas comprometeram a sua participação nesta disciplina de Bioquímica:

$1=$ pouco e $10=$ muito

\begin{tabular}{|l|l|l|l|l|l|l|l|l|l|}
\hline 1 & 2 & 3 & 4 & 5 & 6 & 7 & 8 & 9 & 10 \\
\hline
\end{tabular}

\section{Testes colaborativos e individuais de desempenho}

A avaliação do desempenho dos alunos na disciplina em análise contempla oito testes colaborativos e três testes individuais. Os testes colaborativos envolvem uma etapa individual, que permite a externalização do conhecimento, e uma etapa em grupo, para elicitação e busca por consenso da resolução dos problemas. ${ }^{16}$ Os testes colaborativos correspondem a $20 \%$ do desempenho do aluno (10\% para a etapa individual e $10 \%$ para a etapa em grupo), enquanto que $80 \%$ correspondem ao desempenho em três testes individuais, com pesos diferenciados: 1,2 e 4 . As equações seguintes mostram os cálculos para o desempenho colaborativo, o desempenho individual e o desempenho total.

$$
\begin{gathered}
\mathrm{Tc}=(\mathrm{Tc} 1+\mathrm{Tc} 2 \ldots+\mathrm{Tc} 8) / 8 \\
\mathrm{Ti}=[\mathrm{Ti} 1(\mathrm{x} 1)+\mathrm{Ti} 2(\mathrm{x} 2)+\mathrm{Ti} 3(\mathrm{x} 4)] / 7 \\
\text { D total }=(\operatorname{Ti} \times 0,8)+(\operatorname{Tc} \times 0,2)
\end{gathered}
$$

sendo, $\mathrm{Tc}=$ teste colaborativo $; \mathrm{Ti}=$ teste individual $\mathrm{e} \mathrm{D}$ total $=$ desempenho do aluno na disciplina de Bioquímica.

Destaca-se que, para o cálculo do desempenho do aluno na disciplina apenas são consideradas as notas dos testes colaborativos quando o aluno atinge desempenho igual ou maior do que 5,0 nos testes individuais. Isso impede que eles sejam beneficiados pela nota do grupo sem ter atingido o mínimo necessário para aprovação na disciplina. Os testes colaborativos são corrigidos apenas pelo professor (ou monitores) da disciplina; os testes individuais são corrigidos pelo professor (ou monitores) e, independentemente, pelos alunos. Esta dupla correção tem sido utilizada com sucesso desde $1984 .{ }^{17}$ $\mathrm{Na}$ primeira etapa, os professores e monitores corrigem as questões. Cada item é corrigido pela mesma pessoa, o que permite manter fixos os critérios e o rigor. Na segunda etapa, os testes individuais são devolvidos aos alunos, sem qualquer anotação, para uma nova correção. O professor oferece a resposta ideal para cada problema e os critérios 
de correção; o aluno deve comparar sua resposta com a exposição do professor e atribuir-lhe um valor de 0 a 10 . O caráter do procedimento é eminentemente recuperatório: mesmo que até o momento não saiba a resposta, o estudante precisa entender a questão e sua resposta, ou seja, obter um referencial, para poder atribuir um valor à sua resposta. Quando há pouca divergência (diferenças inferiores a 1) entre as notas do professor e do aluno prevalece a maior nota; quando a diferença é superior a 1, professor e aluno discutem a questão em particular até alcançar o consenso. Esses casos são raros e facilmente resolvidos. ${ }^{17}$

O aluno que não obtém um resultado satisfatório para aprovação pode fazer uma prova de recuperação, desde que a média obtida tenha sido maior ou igual a 3,0. Essa etapa consiste em um teste aplicado aproximadamente dois meses após o término da disciplina. O cálculo da média final é dado pela equação

$$
\mathrm{R}=[(\mathrm{D} \text { total } \mathrm{x} 1)+(\operatorname{Tr} \times 2)] / 3
$$

sendo, $\mathrm{R}=$ nota final após a recuperação e $\mathrm{Tr}=$ teste de recuperação.

Em todas as avaliações, a consulta aos livros e às anotações pessoais é livre. O objetivo deste procedimento é desestimular a memorização de informações. Nas avaliações exige-se a resolução de problemas de mesma ordem cognitiva que os do GD (alta ordem cognitiva, HOCS). Isto impõe um nível de exigência muito maior do que em disciplinas que preveem apenas a reprodução de informações. No Quadro 2 foram apresentados exemplos de questões de alta ordem cogntiva.

Quadro 2. Exemplos de questões de alta ordem cognitiva aplicadas nos testes da disciplina de Bioquímica

Amostras de sangue foram retiradas de pacientes adultos com os quadros clínicos e nas condições seguintes:

a. Diabético não tratado - amostra retirada com o paciente em jejum;

b. Hígido - amostra retirada com o paciente em jejum;

c. Hígido - amostra retirada imediatamente depois de uma refeição;

d. Obeso, sob dieta com severa restrição de carboidratos - amostra retirada com paciente em jejum.

Por um acidente, os rótulos das amostras foram perdidos. Não tendo condições para dosar hormônios, o laboratório responsável fez uma consulta a um(a) farmacêutico(a), pedindo sugestões para a identificação das amostras. Como você responderia à consulta?

Em 1973, Walser e colaboradores propuseram um tratamento nutricional para pacientes com insuficiência hepática apresentando uremia (taxa anormalmente alta de ureia plasmática) crônica, que eram mantidos com uma dieta de baixo conteúdo proteico e valor calórico normal. O tratamento consistia em administrar oralmente sete $\alpha$-cetoácidos, cada um com o esqueleto carbônico correspondente a um aminoácido essencial. Justificar sua concordância ou discordância das afirmações seguintes, referentes à terapêutica proposta:

a. Uremia e balanço negativo e nitrogênio são esperados para indivíduos normais e para os pacientes com o tipo de dieta descrita;

b. Os cetoácidos administrados seriam convertidos em aminoácidos essenciais e utilizados para síntese proteica, levando à queda do nível de ureia plasmática;

c. A administração dos cetoácidos atenuaria o balanço negativo de nitrogênio que os pacientes apresentavam;

d. Aos cetoácidos deveria ser adicionado oxaloacetato para prevenir a sua conversão a corpos cetônicos.

Esse nível de exigência é compatível com a estrutura da disciplina e o suporte oferecido. E resulta em melhores resultados de aprendizagem, de acordo com dados da literatura: os estudantes aprendem mais estudando com métodos de ensino centrados nos alunos do que com aulas expositivas. ${ }^{18-20}$ Isso se deve, principalmente, ao seu envolvimento nas atividades acadêmicas, permitindo que reflitam sobre a experiência de aprendizagem. ${ }^{21,22}$ Portanto, é relevante que o desempenho dos alunos seja avaliado não pela sua performance para memorizar informações, mas para resolver problemas.

\section{Entrevistas semiestruturadas}

Entrevistas semiestruturadas foram realizadas para obter informações adicionais a partir dos padrões observados no questionário e desempenho dos alunos. O objetivo das entrevistas foi verificar a percepção dos alunos sobre o ambiente de aprendizagem e as relações entre o desempenho e a frequência e participação. Para isso, foram realizadas entrevistas com dez alunos, 5 aprovados e 5 reprovados na disciplina (por nota).

A sistematização das informações recolhidas pelas entrevistas foi obtida pela elaboração de mapas conceituais produzidos após a sua transcrição. O mapa conceitual difere dos métodos tradicionais de análise das entrevistas, pois permite dar foco aos conjuntos de relações mais relevantes para a pesquisa. Além disso, esse organizador gráfico fornece resumos rápidos e de qualidade sobre os dados. ${ }^{23}$

As proposições foram elaboradas a partir de trechos da transcrição literal das entrevistas. Algumas modificações foram feitas nas palavras utilizadas pelos entrevistados, mas sem comprometer o sentido da fala. Os mapas foram revistos pelos entrevistados para sua validação. Correspondem, portanto, à interpretação das entrevistas com o objetivo de tornar visíveis os padrões nas respostas dos alunos.

\section{RESULTADOS E DISCUSSÃO}

\section{Desempenho}

Na Tabela 1, tem-se o desempenho dos alunos na disciplina de Bioquímica. Esses valores médios foram calculados de acordo com as fórmulas apresentadas na seção Metodologia.

Tabela 1. Notas finais dos alunos na disciplina de Bioquímica. Número de alunos participantes $=86$. Entre parênteses, valores em porcentagens

\begin{tabular}{cc}
\hline Desempenho & Média (desvio-padrão) \\
\hline Nota $<3,0$ & $6(7,0)$ \\
$3,0 \leq$ Nota $<5,0$ & $30(34,9)$ \\
Nota $\geq 5,0$ & $50(58,1)$ \\
\hline
\end{tabular}

Cerca de $60 \%$ dos alunos foram aprovados na disciplina, de acordo com as normas da Universidade (nota maior ou igual a 5,0) e 7\% tiveram desempenho inferior a 3 e, como consequência, foram reprovados. Os $35 \%$ restantes apresentaram desempenho maior ou igual a 3 , porém menor do que 5 . Esses alunos puderam fazer um teste de recuperação, dois meses após o encerramento da disciplina. Após o teste, apenas 4 alunos foram aprovados (Tabela 2). Assim, o total de alunos que não tiveram desempenho insatisfatório foi 32 (37,2\%).

Tabela 2. Desempenho final dos alunos após a prova de recuperação. Número de alunos participantes $=30$. Entre parênteses, valores em porcentagens

\begin{tabular}{cc}
\hline Desempenho após a recuperação & Média (desvio-padrão) \\
\hline Nota $\geq 5,0$ & $4(13,3)$ \\
Nota $<5,0$ & $26(86,7)$ \\
\hline
\end{tabular}

\section{Frequência e participação}

Como mostra o histograma da Figura 1, 68\% dos alunos foram muito assíduos nas aulas de Bioquímica. Em contraposição, mais 
de $30 \%$ dos estudantes apresentaram número elevado de faltas (intervalos: $20 \%-50 \% ; 50 \%-70 \%$ ). Esse resultado mostra que, apesar do alto número de alunos que faltaram pouco, ou nunca faltaram, o percentual de estudantes com baixa frequência é representativo e tal fato pode ter refletido no seu aprendizado.

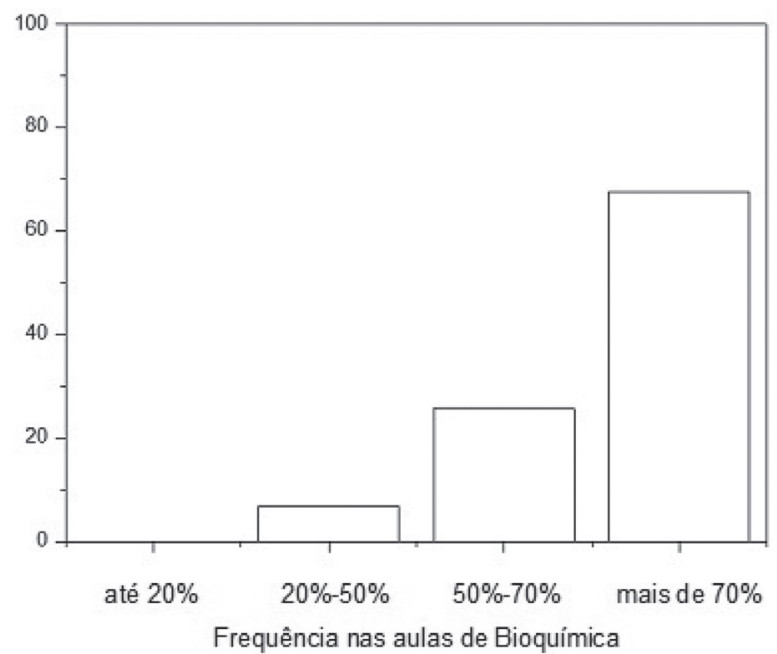

Figura 1. Histograma obtido a partir das respostas dos alunos sobre a frequência deles nas aulas de Bioquímica

De fato, no ensino centrado no professor, a falta traz prejuízos, mas a retomada do aprendizado é favorecida pela explanação sequencial e organizada, característica das aulas expositivas. Com a estrutura colaborativa, a falta aos períodos de estudo, por exemplo, acarreta lacunas de informações integradas que dificultarão ao estudante participar, ou mesmo acompanhar, as discussões que levarão à resolução dos problemas propostos nos grupos de discussão. Além do aspecto cognitivo, o estudante perde a oportunidade de colaborar com seus pares e desenvolver as habilidades que são um dos objetivos do ensino centrado no aluno.

Sobre a implicação da falta em ambientes de aprendizagem centrados no aluno, Koppenhaver ${ }^{24}$ argumenta que a ausência do estudante em sala de aula limita a oportunidade dele(a) de aprender com outros alunos. Contudo, o autor afirma que tal comportamento não apenas nega apenas ao estudante ausente esta oportunidade, mas também nega aos colegas de grupo a possibilidade de aprender com esse estudante. ${ }^{24}$

Nesse sentido, dada a importância da presença e participação dos estudantes nessa estratégia de ensino-aprendizagem, foi preciso

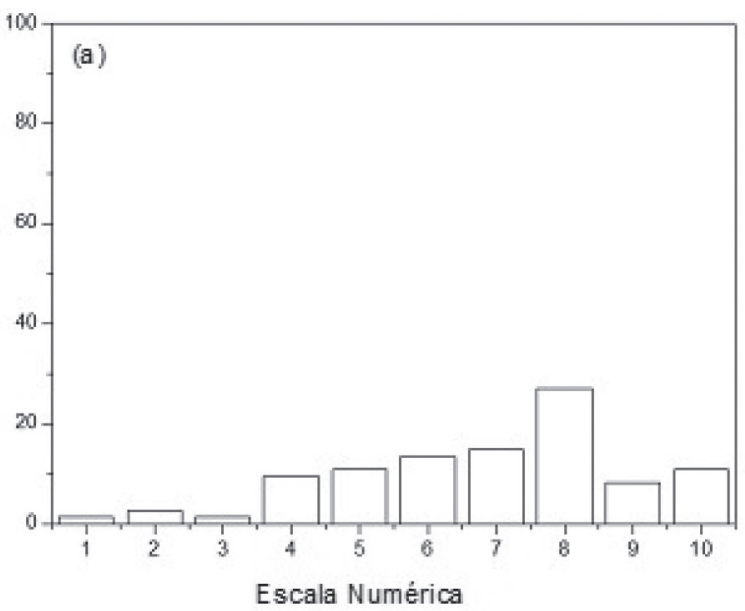

compreender os motivos que levaram os alunos a faltarem às aulas. Os resultados dessa investigação estão apresentados na Figura 2.

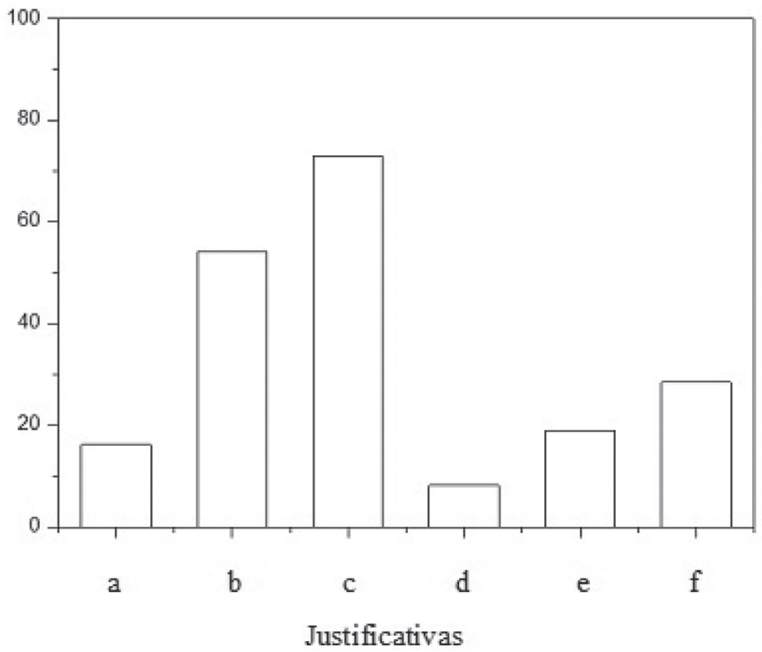

Figura 2. Histograma obtido a partir das justificativas dos alunos para faltar às aulas de Bioquímica (era possível indicar mais de uma opção). a. nunca faltei; $b$. acúmulo de trabalho em outras disciplinas; $c$. antes de provas de outras disciplinas; $d$. acúmulo de trabalho nesta disciplina; e. antes de provas desta disciplina; f. descanso ou lazer

As principais justificativas apresentadas pelos estudantes para faltarem às aulas foram "acúmulo de trabalho em outras disciplinas" e "antes de provas de outras disciplinas". Suas justificativas indicam que estavam sobrecarregados com um número excessivo de aulas e com pouco tempo disponível para estudar. Como consequência, faltavam muito às aulas de Bioquímica, acreditando que assim poderiam atender às demandas das outras disciplinas que cursavam. Contudo, esse comportamento revelou-se incompatível com a efetividade do método de ensino centrado no aluno.

De maneira geral, os resultados mostrados na Figura 2 ilustram a repercussão das estratégias de PE e GD. Quando a matriz curricular é composta majoritariamente por disciplinas que transcorrem por meio de aulas expositivas, os estudantes precisam de tempo para estudar fora da sala de aula. O mesmo não ocorre quando o professor utiliza estas estratégias, uma vez que a construção do conhecimento ocorre em colaboração durante as aulas..$^{3-6}$

A Figura 3 mostra os histogramas obtidos a partir das respostas dos alunos, utilizando uma escala numérica para indicar a participação

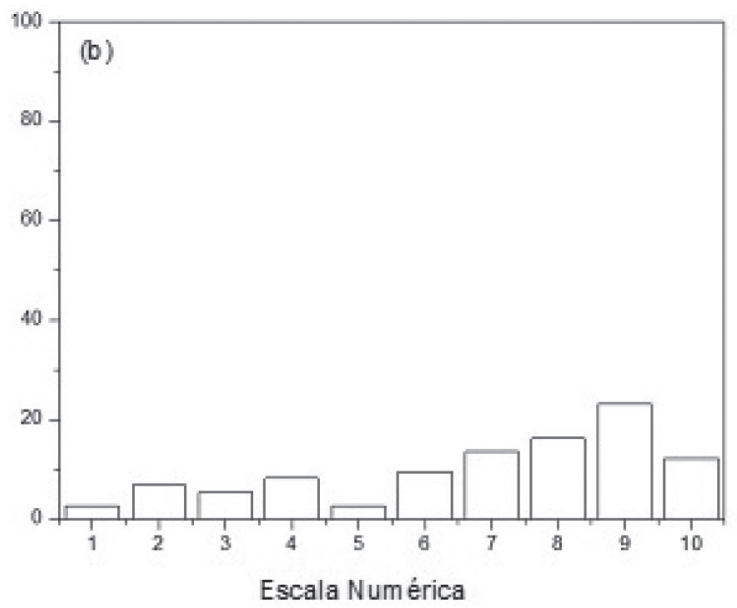

Figura 3. Histogramas obtidos a partir das respostas dos alunos utilizando uma escala numérica $(1=$ pouco e 10 = muito), que indica (a) sua participação nas atividades colaborativas (b) a intensidade com que outras disciplinas comprometeram a participação em Bioquímica 
nas atividades colaborativas, além da intensidade com que outras disciplinas comprometeram a participação em Bioquímica.

Na Figura 3a observa-se que a maioria dos alunos indicou alta participação nas atividades, sendo que $27 \%$ deles assinalaram o nível 8 da escala. Esses valores são indicadores do engajamento dos alunos no PE e GD. É evidente que essa informação é declarativa, mas coerente com as demais medidas avaliadas nesta pesquisa. ${ }^{3-6}$ Por outro lado, mais de $25 \%$ dos alunos indicaram que a participação foi menor ou igual a 5 .

Outras disciplinas, cursadas em paralelo, tiveram grande impacto na disciplina de Bioquímica (Figura 3b). Isso é verificado pelas barras do histograma concentradas nos níveis 6-10 (74\%), com predomínio do nível 9 (23\%). Esse resultado converge com os motivos apresentados pelos alunos para faltarem às aulas de Bioquímica.

Os dados sobre a participação e frequência geraram a necessidade de verificar seu impacto no desempenho. Os resultados estão apresentados na Tabela 3 .

Tabela 3. Influência das variáveis frequência e participação no desempenho dos alunos

\begin{tabular}{lccc}
\hline \multirow{2}{*}{ Variáveis } & \multirow{2}{*}{ Níveis } & \multicolumn{2}{c}{ Situação de acordo com o desempenho } \\
\cline { 3 - 4 } Participação & Reprovado (\%) & Aprovado (\%) \\
& Baixa & 90,0 & 10,0 \\
& Média & 41,0 & 59,0 \\
& Alta & 8,8 & 91,1 \\
\hline \multirow{3}{*}{ Frequência } & Baixa & 60,0 & 40,0 \\
& Média & 72,2 & 27,8 \\
& Alta & 16,0 & 84,0 \\
\hline
\end{tabular}

Para a variável participação calculou-se a razão entre os valores observados e os valores máximos e adotou-se a seguinte classificação: baixa $(0,10 \leq$ Média $\leq 0,40)$, moderada $(0,41 \leq$ Média $\leq 0,70)$ e alta $(0,71 \leq$ Média $\leq 1,0)$. Para a variável frequência considerou-se a seguinte classificação: baixa (entre $20 \%$ e $50 \%$ ); média (entre $50 \%$ e 70\%); alta (mais de 70\% das aulas).

Como era de esperar, os estudantes que tiveram alta frequência ou/e alta participação apresentaram maior desempenho do que aqueles que tiveram baixa frequência ou/e baixa participação. Entre os alunos com alta frequência, $84 \%$ foram aprovados e $16 \%$, reprovados; entre os alunos com frequência baixa ou média, $30 \%$ foram aprovados e $69 \%$, reprovados.

Ainda mais decisiva no desempenho foi a variável participação: dos alunos com alta participação, $91,1 \%$ foram aprovados e apenas $8,8 \%$ foram reprovados. O oposto ocorreu quando a participação foi baixa: $90 \%$ foram reprovados e $10 \%$, aprovados.

De fato, é na colaboração com seus pares para a resolução dos problemas propostos nos PE e GD que, segundo Vygostsky ${ }^{7}$ e seu conceito de zona de desenvolvimento iminente, se processa o necessário amadurecimento das funções mentais. Consequentemente, os alunos que compareceram às aulas e efetivamente participaram das atividades adquiriram maior autonomia e conseguiram resolver problemas de forma independente. Os alunos que tiveram baixa frequência/participação não conseguiram desenvolver as habilidades necessárias para a aprovação na disciplina. Para compreender melhor os fatores que contribuíram para a baixa frequência/participação de alguns estudantes, e também seu baixo desempenho, foram realizadas entrevistas semiestruturadas, apresentadas na seção a seguir.

\section{Entrevistas}

Entrevistas com estudantes reprovados por nota

A Figura 4 apresenta os mapas conceituais elaborados a partir das entrevistas com três dos alunos reprovados (por nota). Destacase que as percepções dos alunos sobre o ambiente de aprendizagem ficaram concentradas do lado esquerdo do mapa e as relações entre participação, frequência e desempenho, do lado direito. Os dois outros mapas (foram cinco estudantes entrevistados), por exibirem convergência de ideias e opiniões sobre os motivos que resultaram no desempenho insatisfatório em Bioquímica, não estão mostrados.

Nas entrevistas, procurou-se verificar as percepções dos estudantes sobre o ambiente de aprendizagem, com foco nos pontos positivos, negativos e nos aspectos a serem melhorados na disciplina.

Os principais pontos positivos, para os cinco alunos reprovados entrevistados, foram a autonomia conferida a eles no processo de ensino aprendizagem, o suporte oferecido pelos professores e monitores e a promoção da aprendizagem. A partir das respostas dos alunos é possível identificar que os elementos que caracterizam os métodos de ensino centrados nos alunos estavam fortemente presentes na disciplina de Bioquímica e ainda que estes foram identificadas como positivos, mesmo pelos alunos reprovados. Conforme Jones ${ }^{21}$ destaca, nesses ambientes os alunos não dependem do professor o tempo todo, pois há valorização da colaboração. Os estudantes resolvem os problemas entre si e o professor oferece orientações (e não respostas prontas) para o desenvolvimento das atividades. ${ }^{21} \mathrm{Em}$ contraste, na aula expositiva, os alunos dependem do conhecimento que é transmitido. ${ }^{10,13}$ Por isso, pode-se dizer que, nos métodos de ensino centrados nos alunos, eles têm mais autonomia e mais iniciativa do que na aprendizagem por recepção, em decorrência de seu maior engajamento no processo de ensino-aprendizagem. Essas opiniões estão manifestadas nos excertos a seguir, retirados das entrevistas dos estudantes II e IV.

Estudante II - [...] esse novo método ele nos dá chance de nós sermos livres, de nós irmos atrás do nosso próprio conhecimento e tudo depende exclusivamente de nós. Um ponto muito bom é que os professores, auxiliares são apenas mentores que nos direcionam, mas somos nós que vamos atrás do conhecimento e isso é muito bom $[\ldots]$ ( sic).

Estudante IV - [...] o que é muito bom é que a gente faz o nosso tempo, por mais que tenha que cumprir aí o roteirinho [...] a gente faz do nosso jeito [...] (sic).

O suporte oferecido pelos professores e monitores foi reconhecido pela permanente disponibilidade para esclarecer as dúvidas e oferecer a assistência necessária para favorecer a aprendizagem. No ensino centrado no aluno, o professor é responsável por monitorar os alunos durante a realização das atividades e fornecer feedbacks, assim ele deixa o papel de narrador. ${ }^{9}$ Esses elementos estam presentes nas falas dos alunos apresentadas a seguir:

Estudante IV - [...] tem uma dúvida ali na hora tem o professor ou os monitores o tempo todo ali para ajudar a gente [...] ( sic).

Estudante $\boldsymbol{V}-[\ldots]$ Eu achava que todo mundo estava disposto a ajudar [...] (sic).

A promoção da aprendizagem é sugerida na fala dos estudantes através da sensação de que eles "aprenderam Bioquímica", mesmo não tendo atingido a nota mínima para aprovação ou ainda pela declaração de que a disciplina não exigia a memorização de informações. Isso pode ser exemplificado pelos seguintes trechos:

Estudante I - [...] o decorar da matéria não é tão importante. Tanto é que a gente faz a prova com o livro do lado. [...] Você foca muito mais na sua inteligência, na sua capacidade diante de um problema, poder raciocinar e tal do que no decorar em si [...] (sic). 


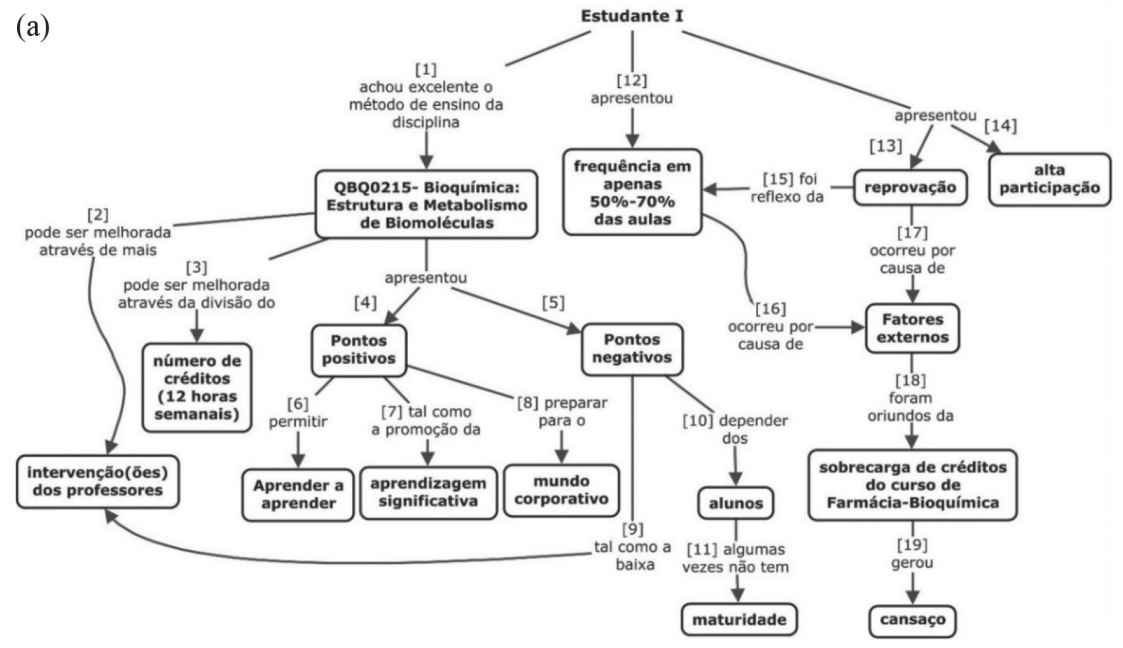

(b)
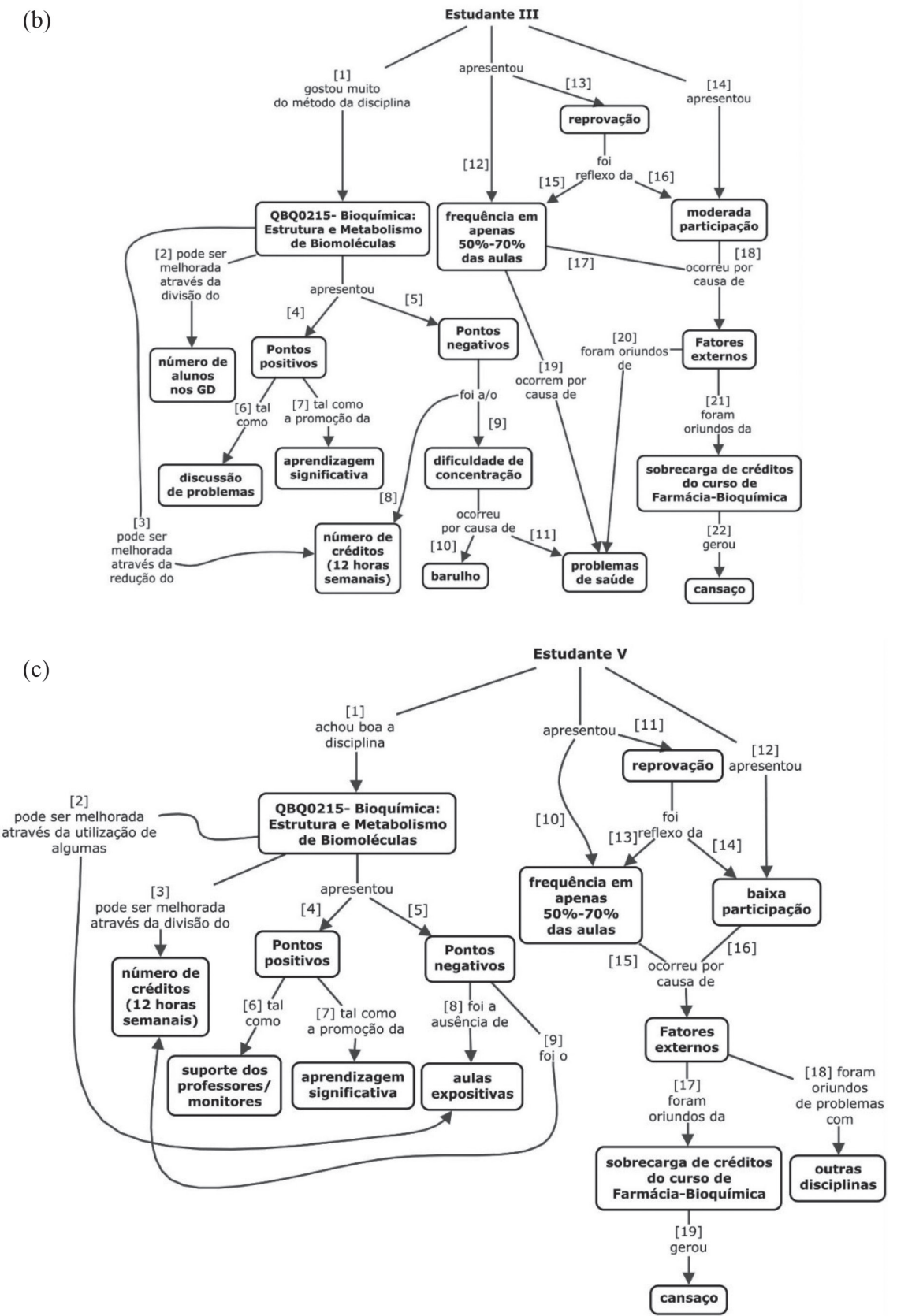

Figura 4. Mapas conceituais elaborados a partir de entrevistas realizadas com alunos reprovados (por nota) na disciplina de Bioquímica 
Estudante III - [...] Por mais que eu não tenha passado na matéria, eu sinto que eu aprendi [...] ( sic).

Estudante $\boldsymbol{V}$ - Então, quando eu reprovei, eu achei que eu não sabia nada [...]. E aí eu.... mas eu fui para outras matérias. Comecei a adiantar matéria e precisava de Bioquímica, por exemplo, química de alimentos. E eu vi que eu entendia, eu vi que eu aprendi. Então, eu acho que eu consigo entender a matéria [...]. Porque eu posso ser reprovado, mas eu acho que eu aprendi (sic).

Outros aspectos positivos indicados pelos alunos reprovados são: a possibilidade de "aprender a aprender", a preparação para o mundo corporativo, a participação ativa e a resolução de problemas de Bioquímica. Van Hout-Wolters et al..$^{25}$ argumentam que os alunos podem aprender a aprender através da prática e da consciência sobre as estratégias de aprendizagem que lhe são mais interessantes e que lhes permitem compreender os conceitos com maior facilidade. Neste sentido, oportunizar no ambiente da sala de aula momentos para que tenham responsabilidade por partes das decisões que podem ou devem ser tomadas é uma forma de ensiná-los a "aprender a aprender". ${ }^{25}$

O principal ponto negativo ou aspecto que precisa ser melhorado na disciplina é a divisão ou redução do número de créditos. Esse ponto esteve presente na fala dos cinco alunos reprovados, ora quando questionados sobre os aspectos negativos, ora quando interrogados sobre os aspectos a serem melhorados na disciplina. Na verdade, é notável que os comentários dos estudantes incidam muito mais sobre a estrutura do curso como um todo do que sobre aspectos específicos da disciplina. Nas palavras dos estudantes:

Estudante I - [...] Uma coisa que até conversei com o professor, mas eu não sei se é possível, seria dividir a Bioquímica. Porque se for fazer todas as tardes no segundo [semestre], você acaba ficando sem tempo para estudar, ficando cansado. E isso, com certeza, eu não sou psicólogo, eu não sei, realmente não sei, mas acaba diminuindo a capacidade de aprender do aluno, de uma maneira geral (sic).

Estudante II - Uma coisa que eu acho que foi negativa foi o tempo. Eu acho que em relação ao tempo, doze horas para você vir de tarde, isso é muito ruim para quem estuda o dia inteiro [...] (sic).

Estudante III - Eu acho que talvez se tiver menos créditos e no sentido de estudar mais sozinha, em casa [...]. Eu tinha sono, às vezes eu não estava disposta. Tinha muita gente falando, não dava para estudar. Então, às vezes, sei lá. Ter uma tarde a menos e ter que estudar nessa tarde ( $\mathrm{sic}$ ).

Estudante IV - Isso, sim e também acho que Bioquímica 12 créditos terça, quarta e quinta das 2 às 6 direto é muito pesado, eu acho que é muito pesado. Por mais que seja, eu gosto de Bioquímica, eu gostei, por mais que seja uma matéria legal, interessante, eu acho muito pesada [...] ( sic).

Estudante $\boldsymbol{V}$ - [...] Não acho que o problema foi com a disciplina, mas como ela está na grade, eu acho que talvez se dividissem que nem a química faz... [...]. Se fosse dividido, eu acho que seria ótimo. Quatro créditos no primeiro semestre e talvez oito no segundo. Isso ajudaria muito (sic).

Outros pontos negativos e aspectos a serem melhorados, para esses alunos, foram a baixa intervenção dos professores, a falta de explicações sobre o método de ensino, dificuldade de concentração oriunda de barulho durante os períodos de estudo, a ausência de aulas expositivas e o alto nível cognitivo exigido nos testes de desempenho. Sobre esse aspecto, é importante destacar que a transição de um método baseado na transmissão de informações para um método centrado no aluno pode ser sido muito abrupta para estes alunos. É possível que para eles (elas) a participação em um ambiente de aprendizagem ativa, que exige maior autonomia e compromentimento com a própria aprendizagem, tenha sido a primeira experiência e isso pode ter contribuído para o insucesso na disciplina. Nesse sentido, acabaram se sentindo frustrados pela ausência de aulas expositivas e pelo nível cognitivo exigidos nos testes de desempenho, uma vez que estavam acostumados com respostas prontas e com a memorização de informações. Outro aspecto a ser considerado deve-se ao barulho indicado por esses alunos. É inevitável que em um ambiente de aprendizagem com cerca de 25 alunos, trabalhando em grupo, o barulho esteja presente. Contudo, destaca-se que os professores discutiram, em vários momentos, com os alunos sobre as regras para a boa condução das atividades.

As relações entre frequência, participação e desempenho ficaram do lado direito dos mapas conceituais. Em todos os mapas é possível verificar um padrão: fatores externos gerados pela sobrecarga de créditos do curso resultaram em cansaço dos estudantes. Essa sobrecarga teve implicações na frequência e participação desses alunos no ambiente de aprendizagem da disciplina de Bioquímica. Esse aspecto pode ser verificado nas seguintes falas:

Estudante I - [...] É, eu acho que problema que todo mundo teve com a Bioquímica, não foi com a Bioquímica [...]. É uma disciplina genial. Uma das que eu mais gostei, embora eu tenha reprovado. [...] o segundo semestre é muito pesado. Então você pode ver... tinha gente que dormia na aula [...]. E assim, acabou que eu não soube me organizar. Em todas as aulas que eu estive presente, sempre fui uma pessoa que participou. [...] se eu estava na aula eu participava. Mas o problema é que eu faltava porque tinha que estudar para alguma outra disciplina [...] (sic).

Estudante II - [...] Porque esse é um método coletivo de aprendizado. Você tem que estar sempre ligado, tem que estar sempre atento. E no meu caso, teve um ponto do curso que eu deixei de ser atento e esse método mesmo sendo muito bom, não foi tão, não foi tão útil para mim [...] (sic).

Estudante III - [...] Porque a gente teve 38 créditos semestre passado. Então, assim ou você estudava ou você ia para a aula, ou você passava a noite estudando. Tinha que dormir muito tarde. Eu não conseguia ter essa rotina ( $\mathrm{sic}$ ).

Estudante IV - [...], então na aula de Bioquímica eu tinha muito sono, muito sono, no começo não, mas foi assim, passando o semestre $[\ldots]$ ( sic).

Estudante V - [...] Eu não vinha na aula! Então, eu ia para o GD e no $G D$ eu não sabia o que falar. Eu ia no GD tentar captar informações [...] Porque eu não tinha ido na aula, porque eu estava preocupado com outras matérias e eu estava tentando organizar e eu acabei não indo $[\ldots]$ (sic).

Tais respostas confirmam os padrões da análise quantitativa: a sobrecarga de créditos comprometeu a participação e frequência dos alunos em Bioquímica. Além disso, é possível verificar a presença de outros fatores externos, tais como problemas de saúde e também fatores internos à disciplina, como a dificuldade de interagir com os colegas do grupo. As impressões dos alunos reprovados foram convergentes com a dos aprovados na disciplina de Bioquímica. $\mathrm{Na}$ próxima subseção, são apresentados esses resultados.

\section{Entrevistas com estudantes aprovados}

A Figura 5 exibe os mapas conceituais elaborados a partir de duas das cinco entrevistas com alunos aprovados. Omite-se os mapas restantes pela justificativa apresentada anteriormente. As percepções dos alunos sobre o ambiente de aprendizagem ficaram concentradas do lado esquerdo do mapa e as relações entre frequência, participação e desempenho ficaram do lado direito, mesmo procedimento utilizado para os alunos reprovados. 

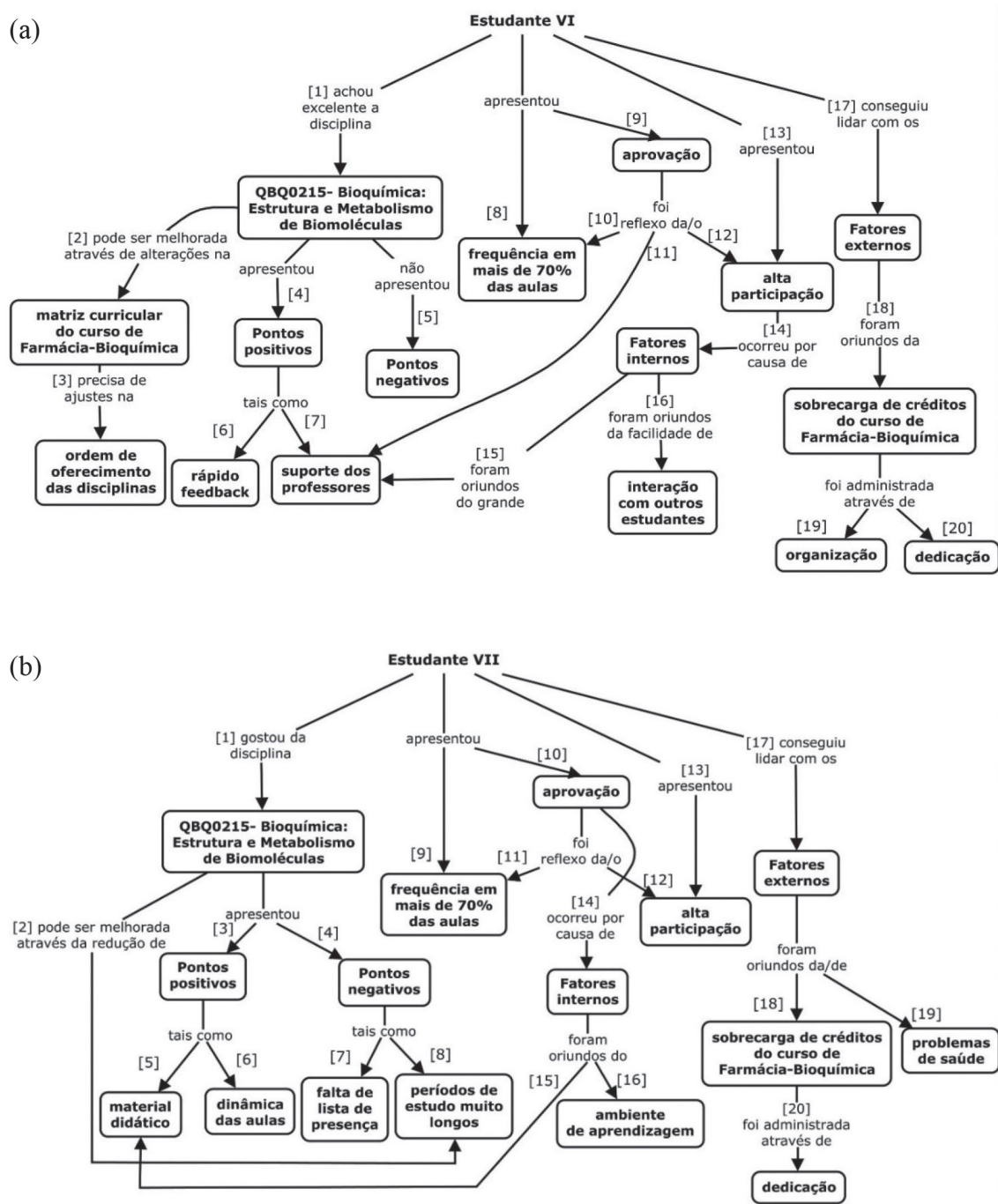

Figura 5. Mapas conceituais elaborados a partir de entrevistas realizadas com alunos aprovados na disciplina de Bioquímica

Os principais pontos positivos, apontados por esses estudantes, com relação ao ambiente de aprendizagem foram o suporte oferecido pelos professores/monitores e o material didático. Outros aspectos foram a dinâmica e qualidade das aulas, participação ativa e autônoma dos alunos, a promoção da aprendizagem e o rápido feedback. Conforme apresentado anteriormente, essas características são muito presentes em ambientes de aprendizagem ativa. ${ }^{9-14}$ Além disso, é importante salientar que estas também foram indicadas pelos alunos reprovados como aspectos positivos da disciplina.

Em relação ao suporte oferecido pelos docentes, os alunos salientaram a disponibilidade dos professores para tirar dúvidas. Nas palavras dos estudantes VI, IX e X:

Estudante VI - [...] Mas aí eu me surpreendi muito positivamente porque a gente tinha um apoio muito grande [...] (sic).

Estudante IX - [...] o suporte também foi uma outra coisa, que também poderia acrescentar, o suporte é perfeito, assim a gente fica bem direcionado, o método, tudo [...] (sic).

Estudante $\boldsymbol{X}-[. .$.$] Você está ali estudando e tem um professor para$ tirar dúvida, primeiro você pergunta para os seus amigos ali da roda, depois você vai até o professor [...] (sic).

O material didático disponibilizado (apostila, livro e softwares) também esteve presente na fala dos alunos aprovados que foram entrevistados. Nos métodos ativos é fundamental que o professor tenha especial atenção à elaboração do material a ser utilizado pelos alunos, pois é a partir desses que os alunos irão se guiar para estudar e resolver problemas. Segundo os estudantes VII e X este aspecto foi positivo na disciplina de Bioquímica.

Estudante VII - [...] Eu achei bem legal isso, e também o material que vocês deram, por exemplo, o software... tipo, aquilo clareou muito, porque no livro é uma coisa muito quadrada, não é? Quando você vê o negócio funcionando, passando pelas etapas, achei que, facilita bastante o aprendizado [...] ( sic).

Estudante $\boldsymbol{X}-[. .$.$] outra coisa também que eu acho que é muito bem$ pensado é a apostila da disciplina que a gente tem. [...] a apostila ela vai direcionando para o seu pensamento ir aprofundando, então as questões... elas fazem você pensar, sabe, te desafia, e depois você consegue ir encontrando a resposta, ou no livro ou você mesmo conclui a sua resposta [...] ( sic).

Para os cinco alunos aprovados que participaram das entrevistas, os pontos negativos e que precisam ser melhorados são os períodos de estudo muito longos, a dependência dos alunos e o peso do último teste de desempenho. Além disso, para esses alunos a melhoria da disciplina de Bioquímica exige alterações no currículo do curso:

Estudante VI - [...]. O que talvez poderia ser feito [...], seria colocar disciplinas que a gente tem no segundo semestre para o primeiro 
semestre para que a gente tivesse mais tempo nesse segundo semestre [...]. Então eu acho que o problema é a quantidade de matéria nesse segundo semestre (sic).

Estudante IX - Ah. Talvez, ah, no curso [...] inteiro eu acredito que... espalhar um pouco [...] para desafogar um pouco porque é muita coisa de uma vez, e as pessoas acabam talvez deixando de ir em Bioquímica, [...] em que é importante ter a sua presença, para cobrir outra coisa [...] (sic).

Diferentes argumentos para lidar com a sobrecarga de créditos foram apresentados pelos estudantes aprovados. Eles declaram que conseguiram a aprovação em Bioquímica através de organização, dedicação ou ainda através da baixa frequência em outras disciplinas. As estratégias de dedicação e/ou organização estiveram presentes nas falas dos estudantes VI e VII, conforme indicado a seguir:

Estudante VI - [...].. Mas eu acho que eu consegui lidar bem. Eu organizei bastante o meu horário. [...] como o meu ensino médio e o meu ensino fundamental eram bem pesados eu acho que eu aprendi a me organizar desde cedo [...]. Talvez se eu tivesse mais tempo eu tivesse estudado mais. Mas eu acho que foi excelente [...] ( sic).

Estudante VII - Ah, na verdade, nem sei porque a gente se vira, não é? (Risos). A gente dá um jeito. Mas é fazendo mesmo, aqui na Bioquímica, que eu falei, estudava em casa, agora nas outras, eu tentava, tipo, estudar entre o intervalo, no almoço ou como eu te expliquei eu como pego ônibus, moro longe, no ônibus dá uma lida, tipo, se virar, para aprender, passei em tudo [...] (sic).

Ou ainda no caso do estudante VIII, que para lidar com a sobrecarga de crédito acabou faltando nas aulas de outras disciplinas, como Química Analítica e Inorgânica. Nas palavras desse aluno:

Estudante VIII - [...] Gerenciar é uma palavra muito bonita (risos). Eu no dia quando não está dando alguma coisa eu começo a faltar com as coisas que dão. Então, não me orgulho disso, mas é que aulas, por exemplo, de Química Inorgânica eu faltei esse semestre, esse semestre no segundo semestre eu não ia, metade as aulas de Analítica eu também não ia. E é assim, o jeito que eu tinha para chegar com tempo... para chegar com tempo para alguma coisa. E daí o problema é que também acumula e daí é o que a gente falava: "a gente tapa o buraco usando a terra de outro buraco, daí você tapa o segundo buraco usando a terra do terceiro buraco e daí você vai caminhando até que de algum jeito que você deu um jeito". Acabou dando certo. [...] Daí foi por isso que eu escolhi a Bioquímica, porque, por exemplo, Analítica eu ia na aula eu não entendia o que estava sendo dado e daí não adiantava eu ir na aula. Então eu preferi dar tempo para Bioquímica... de ficar na aula de Bioquímica (sic).

Essas respostas revelam que, apesar de tanto os alunos aprovados quanto os reprovados terem enfrentado uma alta demanda de créditos, eles adotaram estratégias diferentes para obter o desempenho necessário para a aprovação em Bioquímica. A opção foi determinante para o sucesso. No caso dos alunos reprovados, a opção da maioria foi faltar e/ou não participar ativamente da disciplina de Bioquímica, usando o horário para dedicar-se a outras disciplinas. Os alunos aprovados optaram por superar o excesso de créditos usufruindo das atividades da disciplina para o aprendizado na sala de aula. Como o papel das atividades colaborativas é favorecer a troca social, ${ }^{7}$ os alunos que faltaram e/ou tiveram baixa participação no ambiente de aprendizagem de Bioquímica abandonaram essa possibilidade.

Essa conjunção de fatores interferiu no desempenho dos alunos em Bioquímica, mas apesar disso, fica evidente o efeito positivo desta abordagem inovadora para a aprendizagem dos alunos, mesmo com a influência significativa de fatores externos.

\section{CONSIDERAÇÕES FINAIS}

Nesta pesquisa foram apresentados os resultados sobre o desempenho, frequência e participação dos alunos quando estudam em um ambiente que exige seu engajamento no processo de ensino aprendizagem. A escassez de pesquisas na literatura sobre o impacto dessas variáveis no desempenho, apesar do amplo discurso sobre a importância do engajamento dos alunos para atingir resultados positivos na aprendizagem, foi a lacuna que deu origem a este trabalho. Esperava-se com este estudo confirmar ou refutar a existência das relações supracitadas, que foram claramente ratificadas. Além disso, foi possível verificar que as colaborações entre os alunos foram imprescindíveis para a resolução dos problemas propostos no âmbito da disciplina investigada, uma vez que os alunos que tiveram baixa participação/frequência tiveram seu desempenho prejudicado.

A frequência, mas sobretudo a participação, foi fator determinante para a aprovação em uma disciplina com tal abordagem. Esse resultado é uma clara contribuição para evidenciar a importância da participação ativa dos estudantes na construção do seu conhecimento. Além disso, esta pesquisa revelou a principal razão para as faltas nas aulas de Bioquímica: a sobrecarga de trabalho oriunda de uma estrutura curricular demasiado compacta - a maioria dos alunos tinha 32 ou 34 horas de aula semanais.

O conjunto de resultados obtidos aponta para a necessidade de estruturar currículos harmonicamente centrados nos alunos, contabilizando o tempo real para a aprendizagem que, no caso de disciplinas expositivas, prevê estudos posteriores ao período escolar. Assim, se o período de aulas é integral, o recurso extremo adotado por muitos alunos para estudar para as provas de disciplinas conduzidas por transmissão verbal é faltar em aulas de outras disciplinas, criando um círculo vicioso perverso.

\section{AGRADECIMENTOS}

C.A.T.C. agradece à Fundação de Amparo à Pesquisa do Estado de São Paulo (FAPESP), processo n ${ }^{\circ}$ 2013/25868-3, pela bolsa de doutorado.

\section{REFERÊNCIAS}

1. Zoller, U.; J. Chem. Educ. 1993, 70, 195.

2. Marzzoco, A.; Torres, B. B.; Bioquímica Básica. $3^{\text {rd }}$ ed., Guanabara Koogan: Rio de Janeiro, 2007.

3. Cicuto, C. A. T.; Torres, B. B.; J. Chem. Educ. 2016, 93, 1020.

4. Cicuto, C. A. T.; Torres, B. B.; Resumos do X Encontro Nacional de Pesquisa em Educação em Ciências, Águas de Lindóia, Brasil, 2015.

5. Cicuto, C. A. T.; Torres, B. B.; Enseñanza de las Ciencias 2017, Extra, 5529.

6. Cicuto, C. A. T.; Torres, B. B.; Enseñanza de las Ciencias 2017, Extra, 5535.

7. Vygostky, L. S.; Mind in society: the development of higher psychological processes, Harvard University Press: Cambridge, MA, 1978.

8. Prestes, Z.; Quando não é quase a mesma coisa: traduções de Lev Semionovitch Vigotski no Brasil, Autores Associados: Campinas, 2012.

9. Moreira, M. A.; Ensino, Saúde e Ambiente 2011, 4, 2.

10. Wood, E. J.; Nat. Rev. Mol. Cell Biol. 2001, 2, 217.

11. Wood, W. B.; Gentile, J. M.; Science 2003, 302, 1510.

12. Bligh, D. A.; What's the use of lectures? Jossey-Bass Publishers: San Francisco, 2000. 
13. Powell, K.; Nature 2003, 425, 234.

14. Anderson, W. L.; Mitchell, S. M.; Osgood, M. P.; Biochem. Mol. Biol. Educ. 2005, 33, 387.

15. Ivankova, N. V.; Creswell, J. W.; Stick, S. L.; Field Methods 2006, 18, 3.

16. Fischer, F.; Bruhn, J.; Gräsel, C.; Mandl, H.; Learning and Instruction 2002, 12, 213.

17. Torres, B. B.; Biochem. Educ. 1991, 19, 15.

18. Wilke, R. R.; Advances in Physiology Education 2003, 27, 207.

19. Smith, M. K.; Wood, W. B.; Adams, W. K.; Wieman, C.; Knight, J. K.; Guild, N.; Su, T. T.; Science 2009, 323, 122.
20. Knight, J. K.; Wood, W. B.; Cell Biology Education 2005, 4, 298.

21. Jones, L.; The student-centered classroom, Cambridge University Press: Nova York 2007.

22. Monteiro, L. P.; Smole, K. S.; Educação e Pesquisa 2010, 36, 357.

23. Kinchin, I. M.; Streatfield, D.; Hay, D. B.; International Journal of Qualitative Methods 2010, 9, 52.

24. Koppenhaver, G. D.; Decision Sciences Journal of Innovative Education 2006, 4, 29.

25. Van Hout-Wolters, B.; Simons, R. J.; Volet, S. In New Learning; Simons, R. J., Linden, van der J.; Duffy, T., eds.; Kluwer Academic Publishers: Netherlands, 2000, p. 21. 